\title{
Livro didático de História: representações do 'índio' e contribuições para a alteridade
}

History textbook: representations of the 'Indians' and contributions to alterity

Maria de Fátima Barbosa da Silva*

\section{RESUMO}

A Lei 11.645/2008 objetiva contribuir para a construção de uma educação que valorize as relações étnico-raciais no sentido do resgate das identidades, incentivando o respeito entre os grupos que compõem a nossa sociedade e o questionamento do mito da 'democracia racial'. O acréscimo da temática indígena não implica apenas o acréscimo de conteúdos, mas também novas abordagens, novas metodologias, novos objetos na História Ensinada. Em síntese, implica uma História que rompe com a tradicional visão eurocêntrica e propõe a desconstrução de estereótipos. Este estudo destaca os efeitos da Lei 11.645/2008 no livro didático e sugere como este pode ajudar na construção das identidades, fortalecendo os vínculos identitários dos estudantes e contribuindo para uma maior alteridade.

Palavras-chave: ensino de História Indígena; livro didático; alteridade.

\section{Abstract}

The Brazilian law number 11.645/2008 aims to contribute to the construction of an education which values ethnic-racial relations in the sense of recovery of identities, stimulating the respect between the groups that make up our society and the questioning of the myth of the 'racial democracy'. The addition of the indigenous theme does not only imply the addition of contents; but also new approaches, new methodologies, new objects to the Taught History. In short, it implies a History which breaks with the traditional eurocentric view; and, besides this, it holds a concern about the deconstruction of stereotypes. In this study, we intend to highlight which were the effects of the 11.645/2008 law on the Textbook and how this may help the construction of identities. The apparent changes on the Textbook for it to adjust to the objectives of the law and how these objectives may strengthen the students' identity bonds as well as contribute to a greater alterity.

Keywords: teaching of Indigenous History; textbook; alterity.

\footnotetext{
*Professora da rede estadual de ensino do Rio de Janeiro. Secretaria Estadual de Educação do Rio de Janeiro (SEEDUC - RJ). Rua da Ajuda, 5. Centro. 20040-000 Rio de Janeiro - RJ - Brasil. marifarb@msn.com
} 
Este artigo pretende analisar como o tema das diferenças étnico-raciais vem sendo tratado, atualmente, nos livros didáticos de História, no contexto de aplicação da Lei 11.645/08, com vistas a discutir o impacto dessa abordagem no processo de construção de identidades dos grupos indígenas.

Entendemos que identidade e diferenças são dois processos profundamente imbricados, como afirma Vera Maria Candau:

É importante ressaltar que a identidade se associa intimamente com a diferença: o que somos se define em relação ao que não somos ... As afirmações sobre identidade dependem da diferença, a diferença depende da identidade. Identidade e diferença são inseparáveis ... as diferenças são construídas socialmente e subjacentes a elas, se encontram relações de poder. O processo de produção da diferença é um processo social, não algo natural ou inevitável. ${ }^{1}$

Continuando com a sua exposição, os autores definem assim o conceito de diferença:

Associamos diferença ao conjunto de princípios de seleção, inclusão e exclusão que norteiam a forma pela qual indivíduos marginalizados são situados e constituídos em teorias, políticas e práticas sociais dominantes. Com base nessas diferenças, formam-se grupos distintos 'nós' e 'eles', dos quais o primeiro usualmente corresponde ao hegemônico, ao 'normal', ao 'superior', ao socialmente aceito, ao exemplo a ser seguido. Já o grupo dos 'eles' é integrado pelos excluídos - os 'anormais, 'inferiores', 'estranhos', 'impuros', que precisam ser mantidos à distância em seus 'devidos' lugares. (Moreira; Candau, 2008, p.44-45)

A Lei 11.645/2008 contribuiu para uma necessária discussão a respeito das discriminações a que foi sendo submetido esse grupo formado pelos 'eles', buscando equalizar as desigualdades engendradas com base nessas diferenças socialmente construídas. Segundo o parecer CNE/CEB 11/2000,

Toda a legislação possui atrás de si uma história do ponto de vista social. As disposições legais não são apenas um exercício dos legisladores. Estes, junto com caráter próprio da representatividade parlamentar, expressam a multiplicidade das forças sociais. ${ }^{2}$ 
Essa lei tornou obrigatório o ensino e o "estudo da cultura e da história afro-brasileira e indígena" em escolas brasileiras da educação básica, públicas ou particulares.

Anteriormente, o presidente Lula assinou em seu primeiro ano de mandato a Lei 10.639/2003. Seu dispositivo visava incluir naquele momento apenas a 'temática africana', tornando esse conteúdo componente curricular, preferencialmente nas disciplinas de língua portuguesa, história e artes.

É importante destacar que a Lei 10.639/2003 emergiu do próprio anseio da sociedade, como uma resposta às ações do movimento negro. Não foi imposta 'de cima para baixo', refletiu as lutas dos movimentos sociais. A inclusão da temática indígena no texto da Lei 11.645/2008 também resultou das iniciativas dos movimentos indígenas e indigenistas.

Obviamente, não é apenas por força da lei que esses conteúdos serão operacionalizados na prática, no cotidiano das escolas. De modo geral, é possível constatar que os professores que já adotavam práticas pedagógicas que privilegiavam o respeito às diferenças e uma educação para a promoção nas relações étnico-raciais continuaram adotando essas práticas; os que não adotavam tais práticas pedagógicas não se viram compelidos a adotá-las como resultado de uma imposição legal. O livro didático, como se verá adiante, pode contribuir para a operacionalização desses conteúdos.

A Lei 11.645/2008 é fruto de muitas disputas e representa um passo importante para as relações étnico-raciais, por vários motivos: traz não só a possibilidade de representação de grupos que, historicamente, foram ou marginalizados ou vítimas de estereótipos, mas também uma mudança na própria concepção da História, tradicionalmente 'europeizante', com a qual nos acostumamos.

Daí já é possível vislumbrar algumas dificuldades na aplicação dessa lei, ou por falta de fontes, ou pela dificuldade de superação do modelo de História que sempre esteve presente nos currículos oficiais, não só na educação básica, mas até mesmo no ensino superior de História. Entre os objetivos desse ensino consta a formação inicial dos professores que irão atuar no Ensino Fundamental e Médio. A nova lei implica a revisão de conteúdos curriculares, iniciativa que deveria partir das próprias universidades para melhor atingir a educação básica. 
Objetivando iniciar o atendimento ao dispositivo legal, os editais do Programa Nacional do Livro Didático (PNLD) ${ }^{3}$ começaram a cobrar a adequação dos detentores dos direitos autorais que desejassem constar do seu guia. No edital de 2008 já era possível observar as exigências em relação às temáticas indígenas e africanas. No aspecto geral, já estariam desclassificadas as obras que "veiculassem preconceitos de condição econômico-social, étnico-racial, gênero, linguagem e qualquer outra forma de discriminação". ${ }^{4}$

No edital de 2011 podemos observar que, em relação aos critérios comuns para todas as disciplinas, permanecem os mesmos princípios necessários à construção da cidadania, em relação a essa temática: respeito à pluralidade e à legislação vigente, e não veiculação de estereótipos e preconceitos. Porém, quanto aos critérios de eliminação e qualificação dos livros, especificamente da disciplina de História, podemos observar estes avanços: quanto ao Manual do Professor (MP), deveria conter orientações sobre a História da África e da cultura afro-brasileira, e a respeito da temática indígena deveria orientar os estudantes sobre os temas de Identidade e Diferença.

Dada a impossibilidade de analisarmos todas as coleções de História aprovadas pelo PNLD-2011 em razão do próprio caráter deste trabalho acadêmico, optamos por eleger uma coleção que, segundo o guia PNLD-2011, foi classificada quanto à abordagem da temática indígena e africana, tanto no livro do aluno quanto no Manual do Professor, como de 'conteúdo-crítico reflexivo'.

Essa definição 'crítico-reflexivo' se deve ao fato de o guia PNLD-2011 adotar alguns critérios para classificar os livros didáticos sem buscar uma classificação valorativa ou a emissão de um juízo de valor, pois o guia deixa claro que, em última análise, a escolha do livro didático depende da realidade em que o professor irá utilizá-lo.

De qualquer forma, para efeito de orientação e facilitação na escolha, o guia dividiu os livros didáticos segundo alguns aspectos (perfil dos exercícios, perfil do texto base e perspectiva curricular, entre outros). Quanto à temática indígena e africana, tanto no livro do aluno quanto no MP o guia dividiu as coleções em duas categorias: informativo e crítico-reflexivo.

Os livros de caráter 'informativo' buscaram adequar-se às exigências do edital de seleção 2011 que iriam constar do guia, porém,

sem que tal tratamento seja, necessariamente, vinculado a uma reflexão crítica 
integral e voltada à problematização do tempo presente ou mesmo ao tratamento longitudinal e complexo das relações temporais, seja da História das populações indígenas, seja da História da África e situação dos afrodescendentes no Brasil. Com isso, predomina, para o estudante, uma relação de possibilidade de aquisição informativa e uma condição de análise de tais temáticas ainda, predominantemente, de modo vinculado direta ou indiretamente à cronologia eurocêntrica. (GUIA PNLD-2011, p.24)

Enquadram-se na categoria 'crítico-reflexivo' aqueles em que:

A abordagem de tais temáticas para além da fixação e prescrição de novos conteúdos para o aluno, o que significa imprimir uma problematização complexa entre passado e presente no tocante aos assuntos envolvidos nas exigências e prescrições legais. Tal cenário torna possível, aos alunos, a constituição de um quadro reflexivo mais amplo e denso no tocante à compreensão das contradições, das mudanças e continuidades históricas, da ação dos sujeitos e da emergência de atitudes derivadas de uma consciência histórica capaz de engendrar a ação social ... Com relação às orientações para o professor sobre o tratamento da legislação contemporânea se distinguem por sua capacidade de auxiliar, efetivamente, o trabalho de formação do professor. Recortes nessa direção aparecem em bases historiográficas atualizadas e com densidade teórico-metodológica, além da presença de leitura complementar e indicações pertinentes de fontes de atualização, bem como bibliografia consistente e igualmente atualizada. Além disso, conferem ênfase especial na discussão de tais temáticas, compreendendo a necessidade de o manual do professor ser uma ferramenta capaz de contribuir para o processo de formação continuada do professor. Ainda são em número minoritário e correspondem a 25\% do total. (Guia PNLD-2011, p.24 grifo nosso; ver Gráficos 1 e 2 e Quadro 1)

O foco principal desta análise é observar como as orientações oficiais para os conteúdos da história indígena foram inseridas na coleção, no sentido de se promover uma educação que considere outras matrizes que não apenas a europeia. Além disso, essa educação deve estar em harmonia com a promoção de uma sociedade mais justa e livre de preconceitos, tendo como produto final cidadãos mais conscientes de seu papel, capazes de enxergar e compreender o outro nas suas diferenças. 
É preciso salientar que de todas as 16 coleções aprovadas, apenas quatro conseguiram ser consideradas como de conteúdo crítico-reflexivo pelo PNLD-2011. O dado nos alerta para a necessidade urgente de reelaboração do saber escolar nesses manuais e de ampliação do olhar crítico do professor, no sentido de avançarmos de um conteúdo informativo na direção de uma reflexão mais crítica sobre a temática.

Dessas quatro coleções, optamos por analisar a do professor Alfredo Boulos: História, sociedade e cidadania, da Editora FTD. Essa escolha se deve ao fato de essa coleção, apesar de abordar os conteúdos da História em ordem cronológica - orientação que atualmente é alvo de várias críticas -, ainda assim conseguir obter avaliação positiva do guia PNLD.

O próprio autor justifica a escolha desse tipo de abordagem. Ele afirma que a organização de conteúdos de forma cronológica e integrada permite situar os fatos no tempo, bem como observar sua duração, sucessão e simultaneidade. Além disso, essa abordagem permite a retomada de assuntos em outros capítulos distribuídos ao longo da coleção, como acontece, por exemplo, com o próprio conceito de 'tempo' - este é apresentado no primeiro livro da coleção e, novamente, no capítulo sobre revolução industrial do terceiro livro, para que os alunos compreendam os diversos ritmos em várias sociedades. ${ }^{5}$

Parece-nos que essa coleção demonstra que mesmo numa visão mais tradicional da História, sobre um recorte cronológico e linear, é possível introduzir uma visão crítica, longe de estereótipos e de uma visão eurocêntrica, aproveitando-se também de outras temporalidades. Ou seja, a adoção da perspectiva cronológica linear não elimina uma visão crítica dos conteúdos, que não é necessariamente incluída numa perspectiva temática.

Este trabalho também é fruto de uma inquietude, pois sabemos que em muitos lares o livro didático chega como o único livro a que muitas crianças e adolescentes terão acesso. Justamente por serem pessoas em processo de desenvolvimento, é de extrema importância o cuidado com o conteúdo a que esses jovens estarão expostos. Por exemplo: tais conteúdos irão reforçar ou diminuir o preconceito e a discriminação? O livro didático é, assim, um importante veículo para discursos capazes de contribuir para a construção de significados sobre as relações étnico-raciais e, dessa forma, impactar a constituição de identidades. 
Ao empreendermos tal estudo, consideramos que é central o modo como a narrativa histórica trata a questão das diferenças étnico-raciais em cada contexto. Isso engendra duas outras questões importantes: primeiramente, a desconstrução do 'mito da democracia racial', o que irá nos permitir a formação de cidadãos conscientes da diversidade cultural verificada em nosso país; em segundo lugar - e como decorrência do primeiro aspecto -, é preciso que esses estudantes se vejam representados nas narrativas, entendam a diferença como um direito que lhes é inerente, ao mesmo tempo em que devem respeitar a diferença do outro.

A escolha por uma metodologia para este trabalho foi tão minuciosa e rigorosa quanto a escolha do objeto. Nesse sentido, optamos por fazer uma pesquisa qualitativa com base na metodologia de análise de conteúdo. Essa metodologia nos permitiu definir as nossas categorias de análise a fim de compreendermos como o livro didático (LD) está dialogando com a demanda da inclusão dessas temáticas.

A análise de conteúdo já vem sendo utilizada desde o final do século XIX e, a partir da segunda metade do século XX, vem desenvolvendo diferentes abordagens, sobretudo "na exploração qualitativa de mensagens e informações" ${ }^{6}$ Com base nessa metodologia pretendemos analisar, interpretar e descrever os resultados desta pesquisa buscando atingir um grau de observação da nossa fonte (o LD) que ultrapasse uma leitura comum. Buscaremos captar o sentido simbólico, nem sempre expresso no texto. Para isso, dividimos o material de estudo em unidades menores, que são as categorias de análise.

\section{APRESENTAÇÃO E ANÁLISE DA COLEÇÃO} HISTÓRIA, SOCIEDADE E CIDADANIA

\section{Análise de conteúdo}

Algumas advertências, embora óbvias, se fazem necessárias, antes de avançarmos na análise do LD em questão. A primeira delas diz respeito à subjetividade: embora a metodologia que buscamos adotar nos ajude a limitá-la, estará sempre presente quando se trata de pesquisas qualitativas, sobretudo aquelas que consideram a leitura de textos. Toda leitura, aliás, é suscetível a uma infinidade de interpretações. 
Outra consideração óbvia é que partimos de algumas escolhas, nem sempre ajustáveis a outros olhares. Toda escolha acaba, necessariamente, implicando perdas, embora estas se tornem justificáveis pelo aprofundamento que pretendemos estabelecer nos fragmentos de texto da análise.

A análise de conteúdo operacionaliza-se, basicamente, pela categorização do texto em unidades menores, as quais devem ser 'válidas', 'exclusivas', 'consistentes', 'objetivas' e 'fidedignas'. Além disso, o conteúdo de cada categoria deve ser 'homogêneo'.

Ao criarmos as categorias para nossa análise, partimos da teoria; sobre essa fundamentação alcançaremos a interpretação, ultrapassando uma mera descrição da coleção. Em outra vertente, "a teoria emerge das informações e das categorias" (Moraes, 1999), constrói-se uma teoria com base nos dados, e essa teoria passa a ser também uma interpretação.

Tais categorias emergiram também do próprio texto da lei, além da teoria, quais proporcionando a compreensão da nossa problemática. O que a lei pretende é, entre outras coisas, provocar uma discussão a respeito das relações inter-raciais no Brasil. Nesse sentido elegemos três categorias, que se encontram estrategicamente inseridas no centro dessa discussão: 1) 'encontros'; 2) o conceito de desenvolvimento e a hierarquização das culturas; e, por fim, 3) textos, documentos e imagens que possibilitem a construção de referenciais identitários positivos.

O limite disponível para este trabalho nos leva a apresentar apenas uma das três categorias:

\section{Encontros}

A categoria 'encontros' nos permite compreender as perspectivas dos diferentes grupos étnicos que compõem a nossa sociedade:

Nessa confluência, que se dá sob a regência dos portugueses, matrizes raciais díspares, tradições culturais distintas, formações sociais defasadas se enfrentam e se fundem para dar lugar a um povo novo, num novo modelo de estruturação societária. Novo porque surge como uma etnia nacional, diferenciada culturalmente de suas matrizes formadoras, fortemente mestiçada, dinamizada por uma cultura sincrética e singularizada pela redefinição de traços culturais delas oriundos. ${ }^{7}$ 
Também se procurou elucidar como o LD deu voz a cada uma dessas 'matrizes raciais díspares', se tais vozes estão explícitas, ocultas ou mesmo se foram negadas; se mesmo em se tratando de encontros, o que ainda permanece é a voz daquele grupo que regeu esse 'novo modelo de estruturação societária'.

A inclusão desta categoria de análise se deve à própria constituição étnica da nossa nação. Esses encontros não foram casuais, foram marcados, como todos sabemos, pelo signo da violência. O que queremos ouvir, consultando o LD, é a versão daqueles que foram 'vencidos', retirados do seu espaço natural de convivência (sejam indígenas ou africanos) e inseridos numa nova lógica econômica que defendia a exploração como forma de enriquecimento.

Mais do que procurar vítimas ou culpados, mocinhos ou bandidos, estamos à procura dos discursos textuais que marquem uma ruptura com essa visão dicotômica e contribuam para que o educando compreenda que tais relações foram construídas por sujeitos históricos e foram, portanto, frutos de negociações, de resistências e também de conformações; que esses encontros não aconteceram apenas em um momento específico e reapareceram em outros (por exemplo, durante a montagem da colonização e, depois, nas lutas pela demarcação de terras), e sim que estão presentes no fluxo contínuo da própria história. Queremos interrogar o LD também sobre a capacidade de enunciar para os estudantes as permanências e as descontinuidades das tensões sociais no Brasil.

A coleção História, sociedade e cidadania está dividida em quatro volumes, um para cada ano do segundo segmento do Ensino Fundamental. Propõe-se a apresentar o conteúdo de história de forma integrada e em ordem cronológica. Assim, o estudante, ao dominar o conceito de linha do tempo, tema dos capítulos iniciais, que envolvem a introdução aos estudos da História, estará apto a identificar fatos simultâneos em outros espaços, o que nos ajudará na categorização desses encontros, promovendo uma ruptura com a tradição dominante, pela qual os 'índios', por exemplo, só passariam a ter uma história a partir da chegada do europeu.

Ao se apropriar do conceito da simultaneidade, o professor poderá demonstrar para seus estudantes que os índios também são portadores de uma história 'pré-chegada dos portugueses', e os temas apresentados em ordem cronológica permitem visualizar isso quando se coloca a história desses povos ao lado da história de outros povos. 
Claro que essa forma de divisão não é apenas um estilo narrativo, mas um recurso didático.

Em relação à temática indígena, o primeiro volume reservou o Capítulo 5 para trabalhar "A pré-história brasileira". Do ponto de vista dos encontros, podemos observar que o autor salienta os ritmos de duração histórica marcados de forma diferente da história universal (de cunho europeu), demonstrando que os antigos habitantes de nosso território não estavam em posição de inferioridade em relação aos povos conquistadores, apenas apresentavam um modo de viver diferente. $\mathrm{O}$ autor alerta para a necessidade de se conhecer melhor a história desses povos que são os verdadeiros 'descobridores do Brasil', e também para o perigo de se homogeneizarem grupos indígenas com culturas distintas.

O segundo volume possui como recorte cronológico dois períodos históricos: o período medieval e a modernidade. Tanto para a questão indígena quanto para a africana, não são enunciados pontos de encontro entre as culturas no primeiro período.

O autor até se reporta a uma história anterior à chegada dos portugueses, mas sem delimitação de data, tanto para os africanos quanto para os indígenas. Isso pode confundir o estudante, primeiro por não se elucidar o 'quanto antes' é o tempo dessa chegada; segundo, por recair no mesmo erro já cometido por muitos autores de livros didáticos de história: considerar que durante a Idade Média só havia história para os europeus.

O autor considera outras civilizações, como os bizantinos e os chineses, durante a medievalidade, mas omite os povos indígenas e africanos no mesmo período - algo compreensível pela ausência de fontes e também por questões editoriais.

Em relação à temática indígena, ainda no segundo volume, no capítulo intitulado "Povos indígenas no Brasil" o autor se coloca criticamente perante dois aspectos: a vitimização pela qual os índios são geralmente apresentados nos livros didáticos, e a homogeneização das suas culturas:

Os indígenas já viviam nas terras onde hoje é o Brasil milhares de anos antes da chegada dos portugueses. Apesar disso, com poucas exceções, aparecem nos livros escolares. E, muitas vezes, são mostrados apenas como vítimas, e não como sujeitos da História. 
Além disso, diferentes povos indígenas são muitas vezes chamados pelo nome de índio, como se fossem todos iguais. (Ribeiro, 1995, v.2, p.202)

Em relação ao encontro dos índios com os europeus, o autor desconsidera outras palavras além de 'catástrofe' para caracterizar os efeitos desse encontro. Catástrofe é algo geralmente associado aos eventos da natureza. O que se observa a partir desse encontro é uma verdadeira barbárie, na qual os 'índios' foram sendo expropriados. $\mathrm{O}$ autor assinala os efeitos clássicos, tais como as epidemias trazidas pelos europeus, a superioridade bélica europeia e a escravização dos indígenas, e ainda provoca os estudantes com interrogações:

Mas afinal, o que os povos indígenas têm em comum? Em que são diferentes uns dos outros? Qual o significado da terra para eles? Quais os principais problemas enfrentados por eles no passado? Quais enfrentam hoje? (Ribeiro, 1995, v.2, p.202)

O diálogo com o presente é uma preocupação constante em toda a coleção. Com esse diálogo o autor pretende provocar uma aproximação dos alunos com a realidade dos índios brasileiros. Ao abordar a questão fundiária, os alunos podem também reconhecer pontos de convergência com a realidade indígena e observar como para o índio, ao contrário dos europeus, a terra é de quem nela trabalha, não um objeto negociável, uma mercadoria. Muitas áreas possuem, para os índios brasileiros, uma dimensão sagrada que supera qualquer valor material.

Outra diferença que o LD destaca para os estudantes refere-se à dimensão e ao significado do trabalho. Para os índios, o trabalho não é uma forma de diferenciação social pela renda, mas sim por sexo e idade.

$\mathrm{O}$ autor dedicou três capítulos do terceiro volume para tratar, especificamente, das questões indígenas e africanas, basicamente em relação ao momento da 'montagem da nossa colonização', mas também reportou a participação desses povos em outros contextos. Isso favorece o rompimento com algo já mencionado: o fato de muitos livros didáticos associarem a participação do negro e do índio, por exemplo, apenas nos primórdios da colonização, o que pode ocasionar uma perda da visão do processo histórico em relação a esses atores sociais. 
Em relação ao terceiro volume, cabe destacar ainda alguns dados: seu capítulo de abertura apresenta a montagem da nossa colonização e falha por não abordar as resistências dos nativos do Brasil diante da chegada portuguesa. É nítida a perspectiva da historiografia tradicional, que os apresenta como dóceis e ingênuos.

Porém, o autor apresenta uma ruptura com a visão da história tradicional ao afirmar que os nativos do Brasil foram utilizados nos engenhos da cana-de-açúcar. Para o professor, pode ser interessante levar o estudante à percepção de que ocorreu outro encontro, desta vez envolvendo dois grupos explorados - os negros e os índios -, ambos em posição de subalternidade se comparados aos seus colonizadores, como se vê na Tabela 1 .

O autor apresenta as razões para o declínio do uso da mão de obra indígena e os fatores que levaram à expansão do tráfico negreiro. Ainda que evidencie como razão principal a rentabilidade do tráfico negreiro, não enuncia claramente as formas de resistências efetuadas pelos grupos indígenas, as quais podem também ter contribuindo para o declínio da escravização indígena. $\mathrm{O}$ estudante pode desenvolver a percepção de uma história que é quase sempre fruto das decisões dos grupos dominantes, sem a atuação dos demais, uma vez que não se enuncia a resistência dos grupos indígenas como um dos fatores que contribuíram para a adoção da mão de obra africana. Estes escravos também efetuaram movimentos de resistência que iam do suicídio ao 'fazer corpo mole', além de formarem quilombos, entre outras formas de resistência.

É importante que o estudante compreenda a existência de uma mentalidade de época que 'coisificava' os diferentes em nome do lucro - algo que também não se coloca em evidência na publicação analisada. E os estudantes, na perspectiva de hoje, podem incorrer em anacronismos ou mesmo na emissão de um juízo de valor que limite a sua compreensão desse contexto histórico. Igualmente, não se apontou a base de legitimação para que indígenas e africanos fossem escravizados, não se apresentou, por exemplo, a importância do discurso religioso para validar essas práticas.

Conforme já mencionado, o autor reservou um capítulo inteiro para a questão indígena no segundo volume, no qual aborda o modo de viver dos indígenas antes da chegada dos portugueses e estabelece pontes entre o passado e o presente. 
Percebemos a sucessão de conflitos durante todo o período histórico abordado do terceiro volume - da montagem da colonização até o Segundo Reinado. O livro reporta-se apenas à História do Brasil, já que a coleção apresenta o conteúdo de modo integrado, e é nítida a intenção predatória dos europeus nesse encontro. E o autor não deixa de retratar a participação de indígenas e africanos nos movimentos clássicos de reivindicações e resistências, tais como as guerras guaraníticas e a conjuração baiana.

Embora a lei tenha introduzido a necessidade de uma revisitação historiográfica sobre as questões indígena e africana, o que para muitos autores de livros didáticos tem-se traduzido em uma enorme dificuldade, o autor conduziu com propriedade um aprofundamento com base nas revisitações historiográficas, demonstrando farto conhecimento e incorporando muitas das descobertas recentes. Contribuiu, assim, de modo significativo para ampliação e divulgação do saber, realizando a difícil tarefa de transposição didática do saber acadêmico para o saber escolar. Na seção 'para saber mais' do Capítulo 7 do terceiro volume, "A marcha da colonização na América Portuguesa", por exemplo, o autor demonstra essa aproximação entre o saber acadêmico e o saber escolar. Ao operar com esses novos conhecimentos o autor não apenas oferece aos estudantes o acesso ao saber atualizado, mas também contribui para motivá-los nos caminhos rumo à pesquisa:

Durante muito tempo, pensou-se que a maioria dos índios escravizados pelos bandeirantes foi vendida a colonos do Rio de Janeiro e da Bahia - regiões onde havia falta de trabalhadores, depois que os holandeses passaram a dominar o tráfico negreiro. Mas uma pesquisa recente, do professor John Manuel Monteiro, comprovou que somente uma pequena parte dos indígenas capturados foi vendida para o Rio de Janeiro e a Bahia. A maior parte deles foi vendida para as fazendas de trigo existentes em São Paulo. ${ }^{8}$

Identificamos alguns equívocos de cunho mais conceitual do que propriamente historiográfico, como por exemplo a permanência da nomenclatura 'índios' para os povos do Brasil e 'ameríndios' para os povos da meso-América, como se ambos não fossem habitantes do continente americano. Embora efetue a crítica à homogeneização que essa nomenclatura oferece, o autor acaba por reproduzi-la inúmeras vezes. 
O autor não representa os indígenas do Brasil com base em algumas visões canônicas, como a da indolência. Contudo, embora assinale a grande rentabilidade do tráfico negreiro, enfatiza o domínio de técnicas que os indígenas desconheciam, das quais os africanos tinham amplo conhecimento, e assim acaba por reproduzir outra dessas visões canônicas (contradizendo-se): a de que o trabalhador indígena fora substituído pelo africano por causa da ignorância do primeiro. Isso pode levar os estudantes a um equívoco por induzir uma noção de inferioridade dos indígenas em relação aos povos imigrados da África, ao mesmo tempo em que se subestimam os interesses em jogo.

Buscamos na análise, interpretação e descrição dessa categoria enunciar os pontos de convergências e divergências no encontro entre essas matrizes. $\mathrm{E}$ mesmo compartilhando da ideia de Darcy Ribeiro, de que o encontro 'se dá sob a regência dos portugueses', procuramos também destacar as resistências e negociações e não apenas as dominações, frutos da própria dinâmica social.

Esperamos, também, ter evidenciado o quanto o LD em análise, apesar de repetir alguns pontos de vista tradicionais no ensino de história, contribuiu para a formação de uma consciência histórica que ultrapassa a visão tradicional, ao evidenciar lutas e resistências.

\section{CONSIDERAÇÕES FINAIS}

A demanda aberta pela inclusão das temáticas indígenas e africanas no currículo escolar da Educação Básica, tanto no ensino público como no privado, vem abrindo novos horizontes e possibilidades, mas também tem demonstrado o quanto ainda precisamos nos debruçar sobre essas questões para que elas recebam o tratamento merecido.

Muitas mudanças ainda precisam ocorrer, e não apenas na Educação Básica. É imprescindível incluir no ensino universitário - no currículo daqueles que, futuramente, estarão atuando na Educação Básica - as bases para uma educação que prime pelas relações étnico-raciais.

No LD que foi o alvo de nossos estudos já percebemos algumas mudanças em decorrência da introdução da lei. Outras ainda se fazem urgentemente necessárias, como por exemplo, o 'encontro' entre as matrizes indígenas e 
africanas, pois, de modo geral, cada uma dessas etnias é apresentada de maneira isolada e sempre em relação ao modelo europeu.

No desenvolvimento deste trabalho procuramos adotar a posição de que as identidades passam por um processo de construção. Compartilhamos o pensamento de Stuart $\mathrm{Hall}^{9}$ ao afirmar que elas não são rígidas, são fluidas e híbridas. A Lei 11.645/2008, fruto das lutas sociais, aponta um espaço para construção de uma identificação com outras matrizes que não a europeia. Essa lei vai possibilitar - assim esperamos - o respeito, o entendimento de como se dimensionam as diferenças e o combate às desigualdades. Estas são apenas algumas faces dessa construção que não se faz apenas por força da lei, mas que se efetua sobre os jogos de interesses e disputas com os quais deparamos nas nossas relações cotidianas.

Nesses embates está em pauta a centralidade da dimensão histórica com a busca das raízes e das origens dessas matrizes pela evocação de um passado que legitime tais identidades. A história e o ensino de história passaram a ser essenciais na recuperação da cidadania dos grupos que ao longo da construção do saber histórico e do próprio desenvolvimento de nossa nação foram, de um modo ou de outro, marginalizados.

O saber histórico escolar possui algumas especificidades, entre elas, como vimos, o fato de colaborar na formação dos indivíduos, sobretudo crianças e adolescentes, que ainda se encontram em processo de desenvolvimento. Existe, portanto, uma necessidade subjacente de se compreenderem os discursos ideológicos que podem estar embutidos na própria concepção de história e nos materiais didáticos.

O LD tem se mostrado um importante recurso didático - nem por isso isento de ideologia - para a mediação que ocorre entre o saber acadêmico e o saber escolar. Além disso, é um importante meio para a divulgação das diretrizes curriculares.

Concluímos, pois, que a Lei 11.645/2008 constitui um ótimo ponto de partida para uma sociedade em que o racismo deixe de ser uma prática comum nas relações cotidianas, ainda que muitas barreiras precisem ser superadas. A coleção História, sociedade e cidadania transpôs com sucesso algumas dessas barreiras, outras ainda requerem o olhar atento do professor, o mediador desses conhecimentos. Para tanto é necessária uma formação também pautada na promoção da igualdade entre as raças. 


\section{ANEXOS}

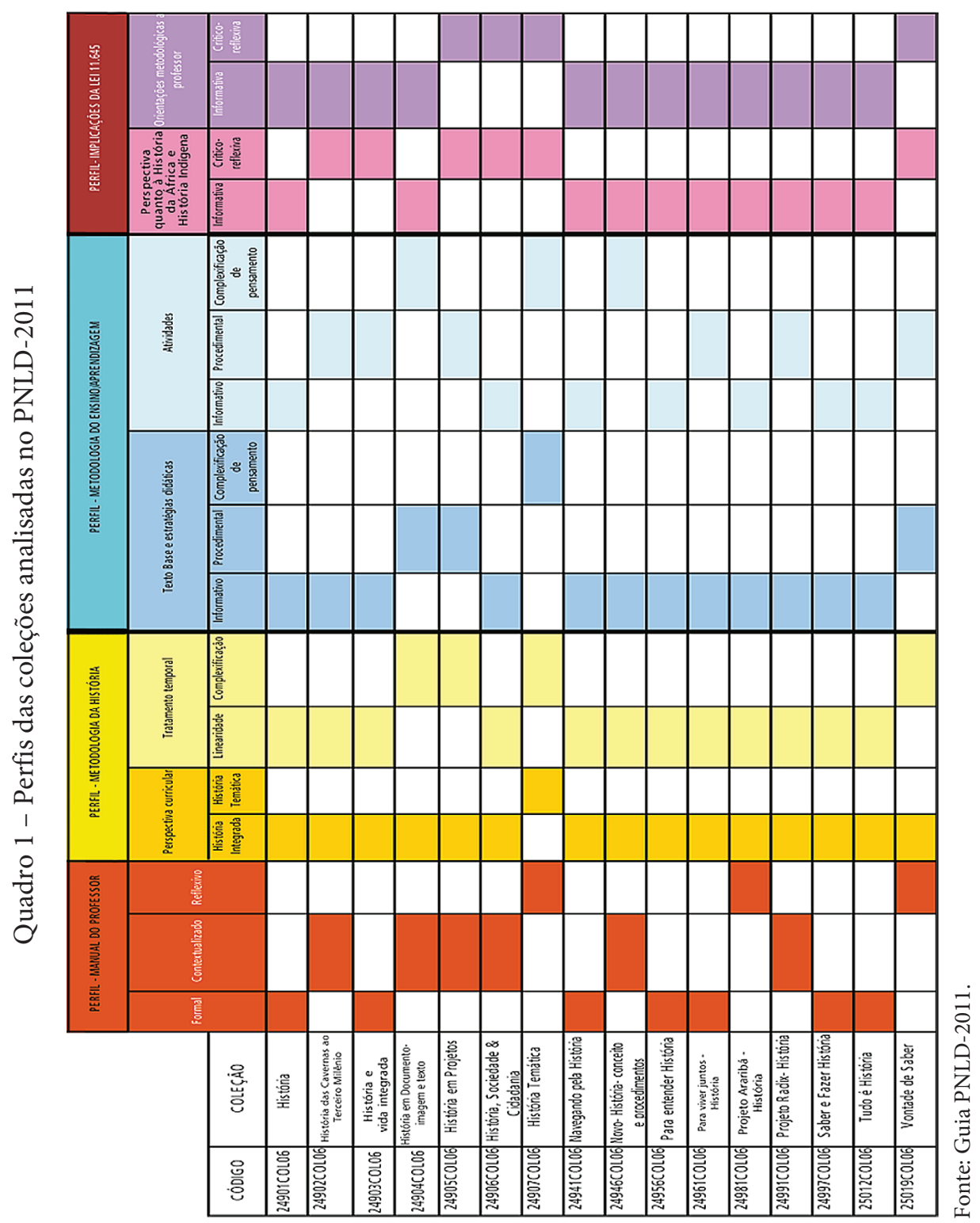


Tabela 1 - Trabalhadores no Engenho Sergipe em 1572

\begin{tabular}{|c|c|c|c|c|c|}
\hline \multicolumn{6}{|c|}{ Trabalhadores no engenho Sergipe em 1572} \\
\hline $\begin{array}{c}\text { Especializados } \\
\text { no fabrico do açúcar }\end{array}$ & Africanos & Índios & $\begin{array}{l}\text { Especializados em } \\
\text { atividades auxiliares }\end{array}$ & Africanos & Índios \\
\hline mestre-de-açúcar & & & vaqueiro & 1 & 1 \\
\hline ajuda do mestre & & & carreiro & 1 & 1 \\
\hline purgador & & & pescador & & 11 \\
\hline ajuda do purgador & 1 & 2 & & & \\
\hline tacheiro & 1 & 2 & serrador & & 7 \\
\hline escumeiro & 1 & & "barcas" & 1 & 4 \\
\hline ajuda do escumeiro & & 3 & \multirow{3}{*}{$\begin{array}{l}\text { Atividades } \\
\text { administrativas }\end{array}$} & \multirow{3}{*}{ Africanos } & \multirow{3}{*}{ Índios } \\
\hline caldeireiro & & 6 & & & \\
\hline moedor & & & & & \\
\hline carapina & & 1 & feitor & & 1 \\
\hline ferreiro & & & \multirow[b]{2}{*}{ Total geral } & \multirow[b]{2}{*}{6} & \multirow[b]{2}{*}{40} \\
\hline calafate & & 1 & & & \\
\hline
\end{tabular}

(SCHWARTZ, Stuart 8. Segredos internos: engenhos e escravos na sociedade colonial (1550-1835). Sảo Paulo, Companhia das Letras, 1988, p. 69. Adaptado.)

Repare que esses dados são de 1572, época em que, no litoral, os indígenas eram numerosos e não havia muitos africanos. A escravização do indígena permitiu o enriquecimento e fortalecimento de uma elite colonial.

Fonte: Boulos Jr., 2006.

\section{Gráfico 1}

PNDL 2011 - Formas de abordagem

da temática e História da África - em \%

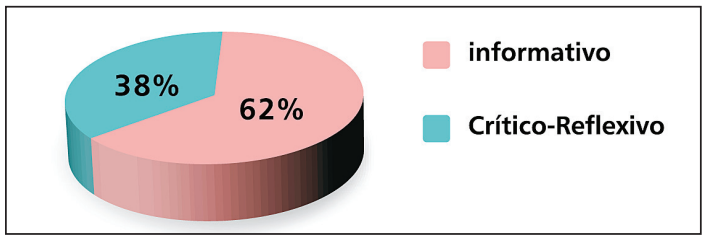

\section{Gráfico 2}

PNDL 2011 - Orientações ao professor sobre o tratamento da temática indígena e História da África - em \%

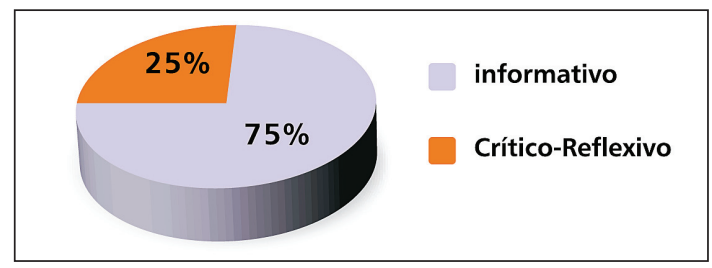




\section{NOTAS}

${ }^{1}$ CANDAU, Vera Maria. Multiculturalismo e educação: desafios para a prática pedagógica. In: MOREIRA, Antônio Flávio; CANDAU, Vera Maria (Org.). Multiculturalismo: diferenças culturais e práticas pedagógicas. Petrópolis (RJ): Vozes, 2008. p.44.

${ }^{2}$ BRASIL. Conselho Nacional de Educação/Câmara da Educação Básica. Diretrizes Curriculares Nacionais para a Educação de Jovens e Adultos. Brasília: MEC/SEF, 2000. p.12.

${ }^{3}$ O Programa Nacional do Livro Didático (PNLD) é uma política do Estado Brasileiro que por intermédio de editais busca promover a qualidade de ensino com base nos livros didáticos. Tem sido um instrumento muito eficiente na divulgação das diretrizes curriculares, como se verá adiante.

${ }^{4}$ Edital PNLD-2008, p.31.

${ }^{5}$ BOULOS JR., Alfredo. História, sociedade e cidadania. 4v. São Paulo: FTD, 2006. Manual do Professor, v.1, p.7.

${ }^{6}$ MORAES, Roque. Análise de Conteúdo. Revista Educação, Porto Alegre, v.22, n.37, p.7-32, 1999.

${ }^{7}$ RIBEIRO, Darcy. O povo brasileiro: a formação e o sentido do Brasil. São Paulo: Companhia das Letras, 1995. p.19.

${ }^{8}$ MONTEIRO, John Manuel. Negros da terra: índios e bandeirantes nas origens de São Paulo. São Paulo: Companhia das Letras, 1994. p.120.

${ }^{9}$ HALL, Stuart. A identidade cultural na pós-modernidade. Rio de Janeiro: DP\&A, 1998. p.13.

Artigo recebido em 18 de março de 2012. Aprovado em 3 de agosto de 2012. 